\title{
SISTEM PAKAR SEBAGAI MEDIA PEMBELAJARAN BERBASIS KOMPUTER DI PROGRAM STUDI ILMU GIZI PADA UNIVERSISTAS DHYANA PURA
}

\author{
Christian Tonyjanto $^{1)}$,Ni Putu Eny Sulistyadewi ${ }^{2)}$ \\ Program Studi Sistem Informasi ${ }^{1)}$ Program Studi Ilmu Gizi ${ }^{2}$ \\ Fakultas Ilmu Kesehatan Sains Dan Teknologi ${ }^{1) 2}$ \\ Universitas Dhyana Pura ${ }^{122}$ \\ christiantonyjanto@undhirabali.ac.id ${ }^{1)}$,enysulistyadewi@undhirabali.ac.id ${ }^{2)}$
}

\begin{abstract}
Expert System is an information system that contains with expert knowledge so that it can be used for consultation. The knowledge of the experts in this system is used as a basis by the Expert System to answer the question (consultation). Expertise is an extensive and specific knowledge gained through a series of training, reading, and experience. Knowledge enables experts to make decisions better and faster than non-experts in solving complex problems. Experts have a tiered nature, top experts have more knowledge than junior experts. The purpose of Expert System is to transfer expertise to a computer, then to someone else (who is not an expert). Expert System is now widely used and found on some websites that are consultation on the world of health. researchers see the opportunity how the application of expert systems that made the goal to create a learning medium where currently common applications used can not be used freely on nutrition students. With the application of expert system, it is expected that students in Nutrition study program get the learning process in analysis and consultation.
\end{abstract}

Key Word : Expert System, science of nutrition, and Web

\begin{abstract}
ABSTRAK
Sistem Pakar(dalam bahasa Inggris :expert system) adalah sistem informasi yang berisi dengan pengetahuan dari pakar sehingga dapat digunakan untuk konsultasi. Pengetahuan dari pakar di dalam sistem ini digunakan sebagi dasar oleh Sistem Pakar untuk menjawab pertanyaan (konsultasi). Kepakaran (expertise) adalah pengetahuan yang ekstensif dan spesifik yang diperoleh melalui rangkaian pelatihan, membaca, dan pengalaman. Pengetahuan membuat pakar dapat mengambil keputusan secara lebih baik dan lebih cepat daripada non-pakar dalam memecahkan problem yang kompleks. Kepakaran mempunyai sifat berjenjang, pakar top memiliki pengetahuan lebih banyak daripada pakar yunior. Tujuan Sistem Pakar adalah untuk mentransfer kepakaran dari seorang pakar ke komputer, kemudian ke orang lain (yang bukan pakar).Sistem Pakar saat ini sudah banyak digunakan dan ditemukan pada beberapa website yang bersifat konsultasi pada dunia kesehatan. peneliti melihat peluang bagaimana aplikasi sistem pakar yang dibuat tujuannya untuk membuat media pembelajaran dimana saat ini aplikasi umum yang digunakan tidak dapat digunakan secara bebas pada mahasiswa gizi. Dengan adanya aplikasi sistem pakar, diharapkan mahasiswa pada program studi ilmu Gizi mendapatkan proses pembelajaran dalam analisa dan konsultasi Kata kunci: Sistem Pakar(Expert System), Ilmu Gizi, dan Web
\end{abstract}




\section{PENDAHULUAN}

Universitas Dhyana Pura sebagai lembaga pendidikan yang saat ini sedang fokus untuk mengembangkan Pariwisata, Manajemen, Psikologi, Pendidikan Anak Usia Dini, Sastra Inggris, Biologi, Gizi, Kesehatan Masyarakat, Rekam Medis, Teknik Informatika dan Sistem Informasi menjadi bagian dari salah satu perguruan tinggi yang ingin memberikan lulusan yang berkualitas secara akademis, berkarakter, professional, perilaku dan spiritual.

Pakar atau ahli ialah seseorang yang banyak dianggap sebagai sumber terpercaya atas teknik maupun keahlian tertentu yang bakatnya untuk menilai dan memutuskan sesuatu dengan benar, baik, maupun adal sesuai dengan aturan dan status oleh sesamanya ataupun khayalak dalam bidang khusus

(https://id.wikipedia.org/wiki/Pakar).

Para pakar saat ini sangat banyak dan sangat diperlukan untuk mengembangkan dunia pendidikan khususnya pada Perguruan Tinggi Negeri (PTN) dan Perguruan Tinggi Swasta (PTS). Hal ini terlihat dengan banyaknya program studi baru, serta menghasilkan lulusan-lulusan yang baik dan bergelar akademik sesuai dengan kebutuhan dunia industri. Dalam dunia kesehatan juga banyak ditemukan pakar-pakar yang pada bidangnya seperti pakar Gizi, pakar Forensik, pakar Jantung dan sebagainya. Untuk menjadi pakar, pelatihan, pendidikan, profesi, publikasi, maupun pengalaman, seorang pakar dipercaya memiliki pengetahuan khusus dalam bidangnya di atas rata-rata.

Dengan melihat kebutuhan dari pakar, Universitas Dhyana Pura menjadi salah satu bagian dari PTS yang konsen terhadap perkembangan Ilmu Pengetahuan dan Teknologi. Terlihat dari banyaknya penelitian yang dilakukan para dosen setiap tahunnya. Tim Peneliti dari Program Studi Sistem Informasi dan Ilmu Gizi, ingin sekali melakukan kolaborasi dalam membuat sebuah rancangan sistem pakar yang dapat membantu proses pembelajaran pada kedua program studi. Dengan adanya sistem pakar yang dirancang khusus ini, diharapkan mahasiswa pada kedua program studi dapat menerapkan keilmuan yang didapat dari proses perancangan hingga menjadi sebuah aplikasi dapat diterapkan dan dikembangkan sesuai dengan keilmuan yang didapatkan mahasiswa selama masa kuliah.

Berdasarkan uraian diatas, tim peneliti melakukan kolaborasi keilmuan yang dimiliki untuk melakukan penelitian dengan judul "Sistem Pakar untuk Media Pembelajaran Berbasis Komputer di Program Studi Ilmu Gizi pada Universitas Dhyana Pura”.

\section{MODEL, ANALISIS, DESAIN DAN IMPLEMENTASI \\ Sistem Pakar}

Beberapa kosep dasar yang harus diketahui sebelum kita melakuakan pembuatan dan pengembangan sistem pakar, komponen utamanya adalah :

1) Tenaga manusia

Mencangkup orang-orang yang memang ahli atau pakar dibidangnya masing-masing. Keahlian tersebut merupakan pengetahuan khusus yang dimiliki seseorang dengan cara belajar dan pengalaman. Pengetahuan tersebut berupa fakta, teori, aturan serta strategi untuk dapat menyelesaikan masalah yang ditanganinya. Dengan pengetahuan tersebut seorang ahli dituntut agar dapat memberikan penjelasan mengenai hasil atau solusi dari masalah tersebut. Selain itu seorang ahli juga dituntut agar dapat mempelajari hal-hal yang beru dari setiap perkembangan yang ada.

2) Perangkat keras (hardware)

Meliputi semua peralatan fisik yang berhubungan dengan sistem pakar tersebut termasuk diantaranya sensor dan antar muka yang membangun antara peralatan fisik dan komputer.

3) Perangkat lunak (software)

Mencangkup program yang akan mengarahkan cara pengoperasian sistem dan menyajikan fungsi-fungsi dari sistem pakar.

b. Komponen sistem pakar

Sistem pakar baru bisa terbentuk dari beberapa komponen yang terdiri dari :

1) Basis pengetahuan

Kaidah-kaidah dan fakta-fakta merupakan suatu pengetahuan seorang ahli yang tersimpan dalam format tertentu. Format atau bentuk yang sering digunakan adalah kaidah produksi. Setiap kaidah terdiri dari satu atau lebih dan setiap klausa dapat diidentifikasikan dengan sebuah kalimat berita. Antara klausa-klausa dalam setiap 
premise dan konklusi dapat dihubungkan dengan penghubung 'dan' atau 'atau'.

2) Mesin inferensi (inference engine)

Mesin inferensi merupakan cara kerja seorang ahli yang berupa pikiran dan pengetahuan dalam penanganan sistem secara umum mesin inferensi memiliki pengetahuan yang sangat luas. Mesin inferensi ini akan menganalisa suatu masalah tertentu untuk selanjutnya akan mencari kesimpulan yang terbaik, dengan demikian sistem ini akan dapat menjawab setiap pertanyaan user. Cara kerja dari mesin inferensi dimulai dari pelacakan, pencocokan kaidah-kaidah dalam basis pengetahuan dengan fakta-fakta yang ada dalam basis data. Terdapat dua buah metode yang dapat membentuk sebuah mesin inferensi, yaitu metode Forward Chaining dan metode Backward Chaining.

3) Antar muka pemakai (user interface)

User interface atau antar muka pemakai adalah suatu bagian yang menghubungkan antara program dengan user. Antar muka pemakai harus bisa menerima informasi yang diberikan oleh pemakai dan memasukannya kedalam bentuk yang dapat dimengerti oleh pemakai. Pada bagian ini akan terjadi dialog antara pemakai dengan sistem, sehingga pemakai dapat mengajukan masalah dalam bentuk 'ya' atau 'tidak'. Program sistem pakar akan menarik kesimpulan berdasarkan jawaban dari pemakai.

Hal ini menarik dari antar muka grafis adalah perintah untuk mengerjakan suatu aktifitas dapat dilihat hanya dengan mengclick suatu icon yang terlihat dilayar dengan menggunakan mose. Dengan variasi icon yang menarik, akan membuat program terlihat lebih hidup. Icon adalah suatu gambar sederhana yang merupakan aktivitas tertentu, yang apa bila icon tersebut di-click maka komputer akan mengerjakan perintah yang sebenarnya tersembunyi dibalik icon tersebut. Selain antar muka berbasis icon, saat ini pemanfaatan jendela (windowing) juga semakin banyak. Jendela adalah suatu daerah pada layar yang berbentuk empat persegi panjang dan dibatasi oleh sebuah pembatas yang biasanya nampak, sehingga pengguna mengetahui batas masing-masing jendela.

\section{4) Development Engine}

Development engine digunakan untuk membangun sebuah sistem pakar, ada data pendekatan didalam sistem pakar yaitu, bahasa pemrograman dan shell sistem pakar. Bahasa pemrograman yang dipakai pada sistem pakar ini adalah bahasa pemrograman PHP. Shell pada sistem pakar merupakan prosessor yang siap dipergunakan atau disesuaikan dengan domain masalah tertentu melalui penambahan basis data yang sesuai.

1. Media Pembelajaran berbasis Komputer

Komputer memiliki kemampuan untuk menyajikan proses pembelajaran interaktif. Krisnadi (2004: 271) menyebutkan bahwa aplikasi komputer dalam pembelajaran, umumnya dikenal dengan istilah Computer Assisted Instruction (CAI) dalam bahasa Indonesia disebut Pembelajaran Berbasis Komputer. Emithu (2010) dalam wahyudiono (2011) CAI adalah aplikasi komputer sebagai bagian integral dalam sistem pembelajaran terhadap proses belajar dan mengajar yang bertujuan membantu siswa dalam belajarnya bisa melalui pola interaksi dua arah melalui terminal komputer maupun multi arah yang diperluas melalui jaringan komputer (baik lokal maupun global) dan juga diperluas fungsinya melalui interface (antarmuka) multimedia.

2. CAI merupakan suatu sistem komputer yang dapat menyampaikan pengajaran secara langsung kepada para siswa dengan cara berinteraksi dengan mata pelajaran yang diprogramkan ke dalam sistem (Nana Sudjana dan A.Riva'i, (2007: 138). CAI juga bermacam-macam bentuknya bergantung kecakapan pendesain dan pengembang pembelajarannya, bisa berbentuk permainan (games), mengajarkan konsep-konsep abstrak yang kemudian dikonkritkan dalam bentuk visual dan audio yang dianimasikan.

3. Menurut Krisnadi (2004: 271) Istilah CAI umumnya menunjuk pada semua software pendidikan yang diakses melalui komputer dimana siswa dapat berinteraksi dengannya. Dari teori yang dikemukakan diatas dapat disimpulkan bahwa penggunaan komputer dalam pembelajaran membantu tercapainya tujuan pengajaran di karenakan siswa dapat langsung berinteraksi dengan materi yang di ajar. 
4. Ilmu Gizi

Ilmu Gizi adalah ilmu yang mempelajari segala sesuatu tentang makanan dalam hubungannya dengan kesehatan yang optimal. Selain itu, ilmu gizi merupakan ilmu terapan yang mempergunakan berbagai disiplin ilmu dasar seperti Biokimia, Fisiologi, Ilmu Penyakit dan beberapa lagi. Sehingga untuk menguasai Ilmu Gizi secara ahli harus menguasai bagian - bagian ilmu dasar tersebut yang relevan dengan kebutuhan Ilmu Gizi (Sediaoetama, 2012).

Menurut WHO dalam Supariasa (2012), menyatakan bahwa secara umum pendidikan gizi bertujuan untuk mendorong terjadinya perubahan perilaku yang positif yang berhubungan dengan makanan dan gizi. Dalam meningkatkan mutu gizi perseorangan dan masyarakat dapat dilakukan melalui 4 (empat) cara yaitu :

1. Perbaikan pola konsumsi makanan yang sesuai dengan gizi seimbang.

2. Perbaikan perilaku sadar gizi, aktivitas fisik, dan kesehatan.

3. Peningkatan akses dan mutu pelayanan gizi yang sesuai dengan kemajuan ilmu dan teknologi.

4. Peningkatan sistem kewaspadaan pangan dan gizi.

Konsultasi gizi merupakan salah satu pelayanan gizi yang sangat penting karena setiap orang mempunyai masalah gizi yang berbeda - beda. Permasalahan gizi yang terjadi saat ini tidak hanya tentang masalah gizi kurang melainkan juga masalah gizi lebih yang disebut dengan masalah gizi ganda (Double Borden). Konsultasi Gizi adalah serangkaian kegiatan sebagai proses komunikasi dua arah untuk menanamkan dan meningkatkan pengertian, sikap, dan perilaku sehingga membantu klien / pasien mengenali dan mengatasi masalah gizi melalui pengaturan makanan dan minuman (Supariasa, 2012).

Tujuan dilakukannya konsultasi gizi adalah untuk membantu klien dalam upaya mengubah perilaku yang berkaitan dengan gizi, sehingga status gizi dan kesehatannya menjadi lebih baik. Orang yang dapat melakukan konsultasi gizi tidak hanya yang mempunyai masalah, melainkan juga seseorang yang sehat yang mempunyai berat badan ideal agar kesehatannya tetap optimal dan bagaimana mencegah penyakit - penyakit yang berkaitan dengan gizi (Supariasa, 2012).

Langkah - langkah yang dilakukan dalam pelaksanaan konsultasi gizi adalah sebagai berikut :

Membangun hubungan dengan klien. Hal ini bertujuan agar klien dapat menjelaskan permasalahan yang dihadapinya, keprihatinan yang dimilikinya dan alasan untuk datang berkonsultasi. Sehingga dapat terjalin hubungan yang positif berdasarkan rasa percaya, keterbukaan dan kejujuran berekspresi.

Identifikasi dan penilaian masalah. Pada langkah ini, seorang konsultan gizi mendiskusikan dengan klien tentang apa yang ingin didapatkan dari proses konsultasi ini. Dalam diskusi ini harus menghindari kemungkinan adanya harapan dan sasaran yang tidak realistis. Sehingga pada langkah ini seorang konsultan gizi dapat mendiagnosis permasalahan dan apa yang diharapakan oleh klien.

Memfasilitasi perubahan teraupetik. Penekanan pada kegiatan dalam langkah ini adalah mencari startegi dan intervensi yang dapat memudahkan terjadinya perubahan. Sasaran dan strategi sangat ditentukan oleh sifat masalah, gaya, dan teori yang dianut oleh seorang konsultan gizi. Pada langkah ini seorang konsultan gizi mencarikan berbagai alternative dan konsekuensi dari masing - masing alternative serta merencanakan tindakan yang diputuskan.

Evaluasi dan terminasi. Penekanan pada langkah ini adalah evaluasi terhadap hasil konseling, dan akhirnya terminasi. Keputusan untuk menghentikan intervensi dan mencari alternative baru merupakan usaha bersama klien dan konsultan gizi.

Untuk mengetahui permasalahan yang dihadapi oleh klien, maka perlu dilakukan pengumpulan data yang dapat dilakukan melalui wawancara dan mencatat dokumen - dokumen yang dibawa oleh klien. Setelah dilakukan pengumpulan data, maka langkah selanjutnya yaitu dilakukan verifikasi, intervensi, penentuan masalah dan penentuan penyebab masalah. Tujuan utama dari pengumpulan data adalah untuk mengidentifikasi masalah gizi dan faktor - faktor yang menyebabkan masalah tersebut. Jenis data pokok yang harus dikumpulkan adalah data antropometri, data biokimia, data klinis dan fisik, data riwayat 
makan, dan data riwayat personal. Dimana, data - data yang sudah terkumpul tersebut akan dibandingkan dengan standar baku atau standar normal sehingga dapat dianalisis permasalahannya (Supariasa, 2012).

\section{Metodologi Penelitian}

Metode penelitian yang digunakan dalam Sistem Pakar untuk Media Pembelajaran berdasarkan penggabungan dari dua keilmuan yang bertujuan untuk memberikan hasil kepakaran. Metode yang digunakan dalam sistem pakar yang dibuat menggunakan metode Best First Search dan Forward Chaining.

\section{Analisis dan Perancangan Sistem}

Pada tahap ini dilakukan perancangan disain sistem pakar untuk media pembelajaran yang meliputi Penentuan lokasi penelitian, pengumpulan data dan penentuan .

a. Penentuan lokasi penelitian

Penelitian dilakukan pada Universitas Dhyana Pura Bali khususnya Program Studi Sistem Informasi dan Ilmu Gizi, yang berada pada Jalan Raya Padang Luwih Tegaljaya Dalung Kuta Utara, Bali (80361).

b. Pengumpulan data

Pengumpulan data atau tahap dokumentasi, yaitu mengadakan pembuatan dokumen yang akan menunjang aplikasi yang akan dibuat agar nantinya sistem bisa dikembangkan lebih lanjut. Dalam tahap ini adalah melakukan pengumpulan dan pengolahan data mengenai materimateri sistem pakar pada Program Studi Sistem Informasi dan gizi pada Program Studi Ilmu Gizi.

c. Penentuan Media Pembelajaran berbasis komputer dan Sistem Pakar

Media Pembelajaran yang dibuat pada penelitian ini berbasis komputer, apabila mahasiswa ingin menggunakan aplikasi ini dapat melakukan instalasi pada komputer atau laptop yang digunakan.

Sedangkan pada Sistem Pakar menggunakan 100 Rules dengan kedalam 5 tingkat, agar dapat dilakukan identifikasi secara spesifik dari hasil konsultasi yang dilakukan.

ERD (Entity Relationship Diagram)
ERD adalah notasi grafik dari model data yang menjelaskan tentang data yang terdapat didalam sistem diagram. Diagram ini menunjukan hubungan antara tabel-tabel yang ada didatabase. Dasar dari Pembuatan Diagram ER dapat dilihat pada gambar 3.1 berikut ini :

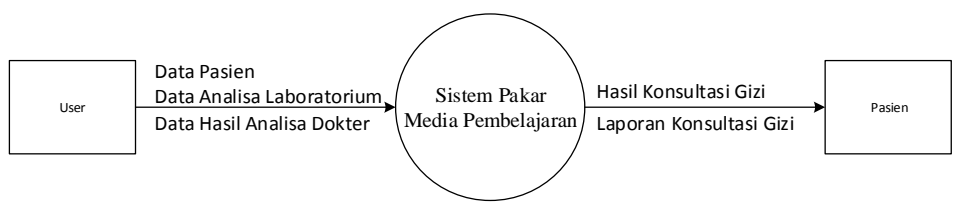

Gambar 1. Diagram Konteks

Aliran data dimulai dari User memasukan data pasien, data analisa laboratorium, dan data hasil analisa dokter yang diinputkan ke sistem yang dirancang dengan terhubung dengan basis data yang telah dirancang untuk kebutuhan sistem pakar sebagai media pembelajaran. Dari hasil analisa menghasilkan hasil analisa konsultasi gizi, yang dapat dipergunakan oleh Pasien. Dengan adanya Diagram Konteks, dapat memberikan penjelasan atau gambaran awal dari merancang kebutuhan basis data dari Aplikasi yang dibuat.

\section{Hasil dan Pembahasan}

Pada bagian ini diuraikan mengenai hasil analisis dan perancangan sistem pakar yang digunakan dalam sistem pakar sebagai media pembelajaran berbasis komputer di program studi ilmu gizi Universitas Dhyana Pura yang sudah dirancang dengan metodologi penelitian pada bab sebelumnya yaitu menggunakan model pengembangan perangkat lunak SDLC hanya sampai tahap ketiga yaitu tahap perancangan.

\section{Analisis Sistem}

Analisis sistem dilakukan untuk menentukan kebutuhan perangkat lunak yang digunakan, sehingga terjadi hubungan antara pembuat sistem dengan pemakai sistem. Analisa sistem meliputi: kebutuhan, kemampuan dan fasilitas yang diharapkan, proses-proses pengolahan data, bentuk data, masukan, dan keluaran yang diharapkan.

$$
\begin{aligned}
& \text { Analisa Permasalahan } \\
& \text { Pada tahap awal yang } \\
& \text { dilakukan } \text { agar dapat }
\end{aligned}
$$


mengetahui gambaran umum mengenai permasalahan yang dihadapi oleh prodi ilmu gizi adalah dengan melakukan analisis permasalahan (problem analysis). Dengan melakukan analisis permasalahan diharapkan dapat memberikan solusi sesuai permasalahan yang dihadapi. Permasalahan yang dihadapi oleh prodi ilmu gizi adalah bagaimana dapat memberikan sebuah aplikasi sederhana yang dapat dipergunakan oleh mahasiswa sebagai media belajar untuk melakukan analisa kebutuhan gizi pada penderita penyakit.

Selama ini sistem yang sudah dimiliki, sudah sangat sederhana tetapi masih perlu melihat lagi dan dikembangkan untuk kebutuhan proses belajar dari mahasiswa. Dengan aplikasi yang akan dirancang dilakukan beberapa penambahan data yang menjadi bagian untuk dilakukan analisa untuk keperluan kecukupan gizi dari penderita penyakit.

\section{Analisa Kebutuhan}

Setelah melakukan analisa permasalahan, dilanjutkan dengan analisa kebutuhan (requirement analysis) user sebagai pengguna dari aplikasi tersebut. Dalam hal ini pengguna sistem adalah prodi ilmu gizi yang akan menggunakan aplikasi ini sebagai media pembelajaran. Adapun instrument yang digunakan sebagai bahan untuk menganalisa kebutuhan sistem adalah dengan melakukan studi literature dari sumber-sumber yang dapat dipercaya.

Studi literature digunakan untuk mendapatkan informasi mengenai detil data yang akan menjadi masukan data pada aplikasi media pembelajaran yang dirancang.

\section{Analisa Struktur Sistem}

Pada tahap Analisa Struktur Sistem Pakar sebagai Media Pembelajaran yang dirancang dalam penelitian ini dibagi menjadi tiga bagian yaitu input, proses dan output.

Analisa Input

Input dalam sistem ini dibutuhkan untuk melakukan proses analisa kepakaran gizi, dilakukan dengan menggunakan beberapa metode. variabel yang diperlukan sebagai berikut;

1) Data Hasil Pemeriksaan Laboratorium dari Pasien

2) Hasil Analisis Dokter yang menangani permasalahan Pasien

dengan dua data yang dimiliki tersebut dapat dijadikan dasar sebagai pengambilan keputusan secara sistem agar dapat diketahui berapa jumlah kebutuhan gizi oleh pasien. Serta juga dengan data tersebut dapat menjadi data awal bagi mahasiswa untuk bisa melakukan proses input pada sistem yang dirancang. Seperti pada Gambar 2.

\section{Analisa Output}

Output dari sistem ini merupakan sebuah informasi dari input data hasil pemeriksaan laboratorium dan hasil analisa dokter yang menghasilkan hasil kecukupan gizi bagi penderita penyakit tertentu untuk memenuhi kebutuhan ketercapaian gizi serta membantu proses penyembuhan bagi pasien. Seperti pada Gambar 3. 

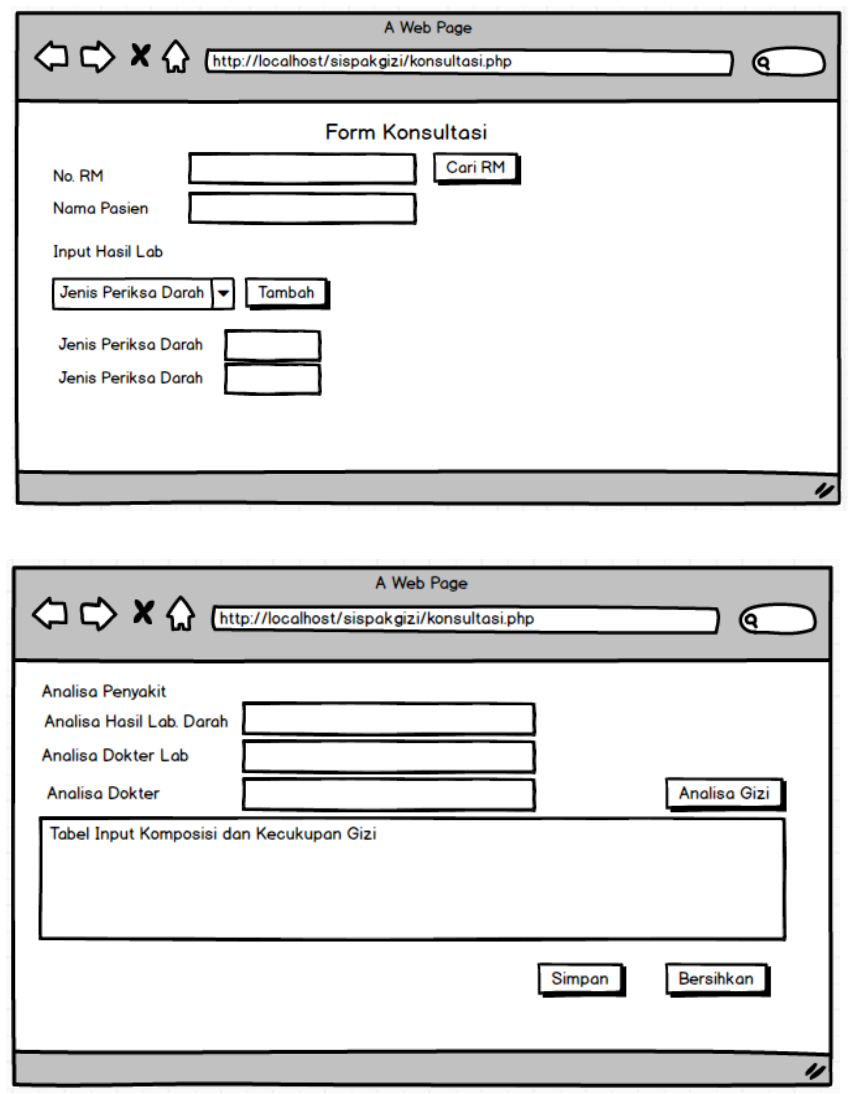

Gambar 2. Tampilan Halaman Konsultasi

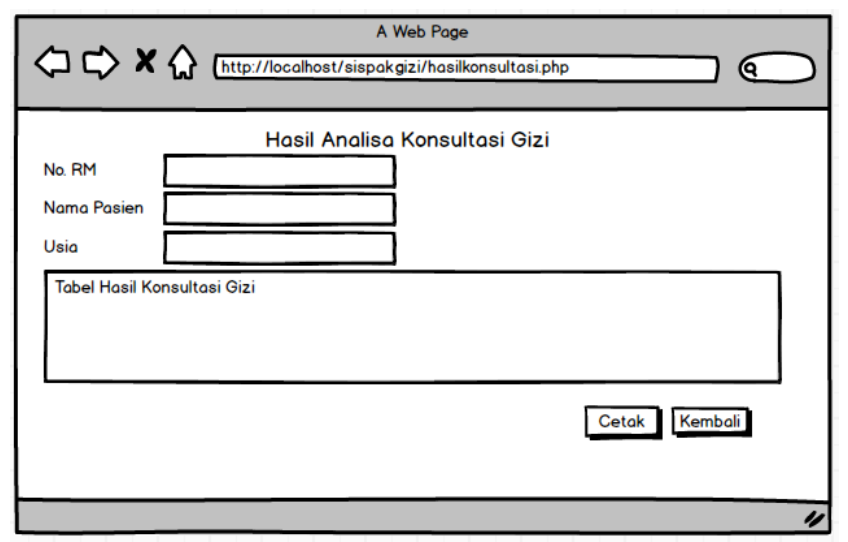

Gambar 3. Tampilan Halaman Hasil Konsultasi

\section{Simpulan}

Berdasarkan penelitian yang sudah dilakukan sampai tahapan ini dari sistem yang dibangun mengenai Sistem Pakar sebagai Media Pembelajaran di Program Studi Ilmu Gizi Universitas Dhyana Pura, maka dapat disimpulkan, Berhasil di analisis dan dirancang menggunakan metode pengembangan perangkat lunak SDLC pada pengembangan Basis Data dan Teori Sistem Pakar. Membantu kebutuhan program studi ilmu Gizi, untuk memberikan aplikasi media pembelajaran bagi mahasiswa dalam analisa kebutuhan gizi.

\section{Daftar Pustaka}

[1] _. 2012. Definisi dan Pengertian Web Menurut Para Ahli. [Online]. Tersedia: http://www.sambureki.com/definisi/definisidan-pengertian-web-menurut-para-ahli.html. [29 September 2012, 17.32 WIB].

[2] Dewanto, I. Joko. (2006). Web Desain (Metode Aplikasi dan Implementasi). Yogyakarta: Graha Ilmu.

[3] Kadir Abdul, Dasar Pemrograman Web Dinamis Menggunakan PHP, Andi Offset, Yogyakarta, 2003

[4] Nurtahyudi. [Online]. Tersedia: http://elib.unikom.ac.id/files/disk1/316/jbptu nikompp-gdl-nurtahyudi-15762-313_babii.pdf

[5] Rachmawati. [Online]. Tersedia: http://elib.unikom.ac.id/files/disk1/527/jbptu nikompp-gdl-rachmawati-26318-5unikom_r-i.pdf. [29 September 2012, 17.35 WIB].

[6] Saleh, Abdul Rahman. (2010). Membangun Perpustakaan Digital: Step by Step. Jakarta: Sagung Seto.

[7] Saputro, Hendra W. (2007). Pengertian Website dan Unsurunsurnya.[Online].Tersedia: http://www.balebengong.net/topik/teknologi /2007/08/01/pengertian-website-dan-unsurunsurnya.html. [29 September 2012, 17.30 WIB].

[8] Sediaoetama, A.D. 2012. Ilmu Gizi Untuk Mahasiswa dan Profesi Jilid I. Jakarta : Dian Rakyat

[9] Supariasa, IDN. 2012. Pendidikan dan Konsultasi Gizi. Jakarta : EGC.

[10] Sutarman S.Kom, Membangun Aplikasi Web dengan PHP dan MYSQL, Graha Ilmu, Yogyakarta, 2003

[11] Suyanto, Asep Herman. (2007). Step by Step: Web Design Theory and Practices. Yogyakarta: Andi Offset.

[12] Syahalong. [Online]. Tersedia: http://syahalong.blogspot.co.id/2010/05/prop osal-skripsi-surat-menyurat.html 